\title{
The Construction and Evaluation of Human Resources Professional Norms Model
}

\author{
Hou Ran \\ College of economics and management \\ He Bei University of Science and Technology \\ Shijiazhuang Hebei, China \\ e-mail: 402348253@qq.com
}

\section{Shan Nannan}

College of economics and management

He Bei University of Science and Technology

Shijiazhuang Hebei, China

e-mail: 15903219372.com@139.com

\author{
Hao Zan \\ College of economics and management \\ He Bei University of Science and Technology \\ Shijiazhuang Hebei, China \\ e-mail: 15032180227@139.com
}

\begin{abstract}
The developing of the globalization of the world economy and regional economic integration, makes China, which is in the period of social transformation, have the situation such as: professional norms empty, professional norms confliction, professional norms unclear, professional norms dysfunctional. With the fuzzy mathematics theory, the paper sets up a quantitative model in the process of establishing the model, through experts scoring, using the analytic hierarchy process confirms the weight of each index system,finally the paper calculates the evaluation result.Then we apply the above results into a score $P$, which measure the organizational human resource professional norms system is sound and reasonable or not, in order to provide guidance and reference for building an excellence professional norms system. Using this method not only realizes the professional norms transformation from quantitative research to qualitative research, so that the model is more scientific authoritative、maneuverability, and avoid the subjective factors playing a leading role in establishing the professional norms system.
\end{abstract}

KeyWords-Human Resources;professional norms ;Fuzzy Comprehensive Evaluation Model;experts scoring;analytic hierarchy process

\section{INTRODUCTION}

Professional norms are kinds of written or unwritten behavioral demands that maintain normal or reasonable professional activities【1】. These behavioral demands are formed and developed in the long term of practice activities, which is the rules, orders disciplines, and customs obeyed by us.Some of them reflect the relationship between people and objects in the practice activities, such as: the operation instructions and security requirements of professional practices, which belong to the technology system; others reflect the relationship between us, for instance: the social relationship and emotional entanglements between people in the practice activities, which belong to human nature. An organization, if owns the perfect professional norms, will benefit for realizing the targeted goals and saving human capital; as well as improving the whole quality of human resources. However, the professional norms of all kinds of organizations are imperfect in China, and these organizations are short of effective approach to evaluate the professional norms. Therefore, building a set of professional norms evaluation quantitative model has the vital practice meanings for guiding the human resources professional norms system.

\section{SETTING UP A HUMAN RESOURCES PROFESSIONAL NORMS FUZZY EVALUATION MODEL}

The building of the human resources professional norms system should have characteristics of level and logic. professional norms are the effective integration of the ethical attitude and behavioral element for each level, department, post and staff 【2】. As for the balance of the professional norms, the paper adopts two approaches 【3】: one is direct measure, mainly focused on the result of professional norms system. When the professional norms is perfect, the positive behavior of staffs is more clear, because staffs restricted by the clear norms, they are able to confirm their own duties, master the practice instructions, and make the organization run smoothly and definitely, finally realize operation efficiency maximized; the other one is indirect measure, mainly focused on the result made by deficiency or imperfect professional norms (generally the loses of the organization). Because the imperfect of the professional norms system will cause responsibilities of anomie, staffs uneven, operation instructions unclear, which affect the effective running of the organization .

We think that the design of the human resources professional norms index system should abide by the following principles: Firstly, it is able to abjectly and truly reflect the real situation of the norms, each index should be designed scientific and reasonable 【4】. Secondly, the design should concrete, easy understand and control. Measurable index could be carried on quantitative analysis, carrying on qualitative analysis for unmeasured index, and taking quantitative analysis with scored by experts. The paper considers that the establishment of the system and model should have the functions of description, interpretation, evaluation, prevention and assistance. on the 
basis of looking up relative references, we take 3 first grade index, 16 second grade index to evaluate whether the norms are perfect or not. See table 1 .

Among them, the definition of the first grade index:

TABLE I. HUMAN RESOURCES PROFESSIONAL NORMS MODEL

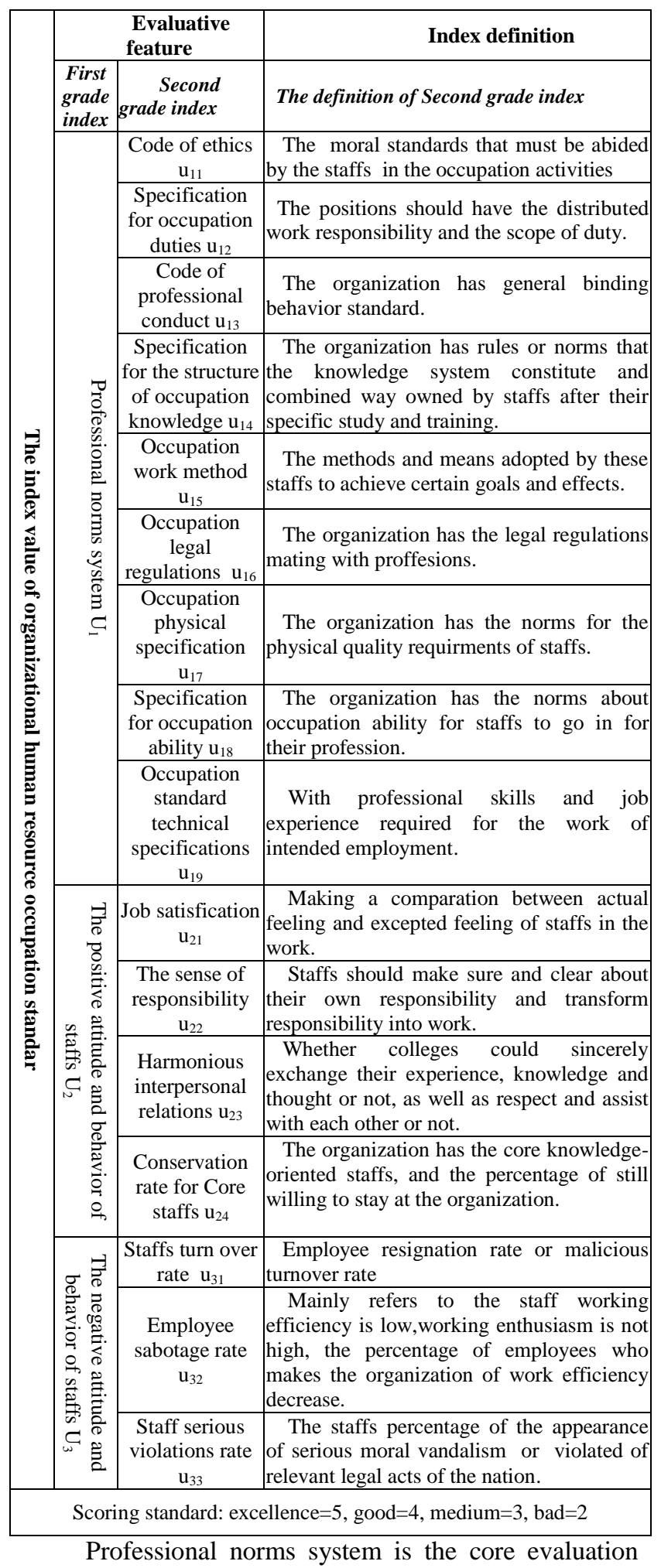
index of the human resources management, including code of ethics【5】, specification for occupation duties, code of professional conduct, specification for the structure of occupation knowledge, occupation work method, legal regulations, occupation physical specification, occupation ability, occupation standard technical specifications.

The positive attitude and behavior of staffs 【6】 aims at measuring the profit brought by staffs when professional norms exist. The main index including: job satisfication 【 7 】, the sense of responsibility, harmonious interpersonal relations and conservation rate for core staffs.

The negative attitude and behavior of staffs aims at measuring the attitude and behavior that harm for the organization, when lacks of the professional norms. The main index including: staffs turnover rate, employee sabotage rate, staff serious violations rate.

\section{THE SITUATION OF EVALUATING HUMAN RESOURCES PROFESSIONAL NORMS SYSTEM}

Assumptions used for human resources professional norms model:

Assumption 1: The organization should satisfy the basic demand of each index.

Assumption 2: The raters should do not have apparently personal preferences, in order to achieve the justify.

Assumption 3: The higher scores the organization gets, the better is the professional norms system; the lower scores the organization gets, the worse is the professional norms system.

Assumption 4: Getting rid of the affect of staffs positive behaviors and negative behaviors from human resources management, only taking the affect from professional norms system into consideration.

The assessors of the model need grasp the relative evaluation information, then applying fuzzy comprehensive evaluation model to quantize the professional norms【8】. Assumed four evaluation grade, namely: \{ excellence, good, middle, bad \}, the corresponding score is respectively five, four, three, two $\}$. These following steps for the evaluation of human resources norms model:

Step 1: using the analytic hierarchy process 【9】 to confirm the weight on the index. adopting the experts scoring method 【10】 for confirming, see table 2. The most important for the organization is to set up the professional norms system; then to encourage the positive attitude and behavior of staffs; lastly, to avoid the negative attitude and behavior of staffs.

TABLE II. DETERMINE THE WEIGHE OF THE FIRST OF THE LEVEL INDEX

\begin{tabular}{|c|c|c|c|c|}
\hline $\mathbf{U}$ & $\mathbf{U}_{\mathbf{1}}$ & $\mathbf{U}_{\mathbf{2}}$ & $\mathbf{U}_{\mathbf{3}}$ & weight $\mathbf{W}$ \\
\hline $\mathbf{U}_{\mathbf{1}}$ & 1 & 3 & 5 & 0.48 \\
\hline $\mathbf{U}_{\mathbf{2}}$ & $1 / 3$ & 1 & 3 & 0.33 \\
\hline $\mathbf{U}_{\mathbf{3}}$ & $1 / 5$ & $1 / 3$ & 1 & 0.19 \\
\hline \multicolumn{6}{|c}{$\mathrm{CR}=-3.1422 \mathrm{CI}=-1.8225 \mathrm{RI}=0.58$} \\
\hline
\end{tabular}


TABLE III. DETERMINE OCCUPATION STANDARD SECOND LEVEL INDEX WEIGHT

\begin{tabular}{|l|c|c|c|c|c|c|c|c|c|c|}
\hline $\mathbf{U}_{\mathbf{1}}$ & $\mathbf{U}_{\mathbf{1 1}}$ & $\mathbf{U}_{\mathbf{1 2}}$ & $\mathbf{U}_{\mathbf{1 3}}$ & $\mathbf{U}_{\mathbf{1 4}}$ & $\mathbf{U}_{\mathbf{1 5}}$ & $\mathbf{U}_{\mathbf{1 6}}$ & $\mathbf{U}_{\mathbf{1 7}}$ & $\mathbf{U}_{\mathbf{1 8}}$ & $\mathbf{U}_{\mathbf{1 9}}$ & weight $\mathbf{W}_{\mathbf{1}}$ \\
\hline $\mathbf{U}_{\mathbf{1 1}}$ & 1 & 3 & 3 & 5 & 5 & 7 & 7 & 9 & 9 & 0.115 \\
\hline $\mathbf{U}_{\mathbf{1 2}}$ & $1 / 3$ & 1 & 3 & 3 & 5 & 5 & 7 & 7 & 9 & 0.114 \\
\hline $\mathbf{U}_{\mathbf{1 3}}$ & $1 / 3$ & $1 / 3$ & 1 & 3 & 3 & 5 & 5 & 7 & 7 & 0.113 \\
\hline $\mathbf{U}_{\mathbf{1 4}}$ & $1 / 5$ & $1 / 3$ & $1 / 3$ & 1 & 3 & 3 & 5 & 5 & 7 & 0.112 \\
\hline $\mathbf{U}_{\mathbf{1 5}}$ & $1 / 5$ & $1 / 5$ & $1 / 3$ & $1 / 3$ & 1 & 3 & 3 & 5 & 5 & 0.111 \\
\hline $\mathbf{U}_{\mathbf{1 6}}$ & $1 / 7$ & $1 / 5$ & $1 / 5$ & $1 / 3$ & $1 / 3$ & 1 & 3 & 3 & 5 & 0.111 \\
\hline $\mathbf{U}_{\mathbf{1 7}}$ & $1 / 7$ & $1 / 7$ & $1 / 5$ & $1 / 5$ & $1 / 3$ & $1 / 3$ & 1 & 3 & 3 & 0.109 \\
\hline $\mathbf{U}_{\mathbf{1 8}}$ & $1 / 9$ & $1 / 7$ & $1 / 7$ & $1 / 5$ & $1 / 5$ & $1 / 3$ & $1 / 3$ & 1 & 3 & 0.108 \\
\hline $\mathbf{U}_{\mathbf{1 9}}$ & $1 / 9$ & $1 / 9$ & $1 / 7$ & $1 / 7$ & $1 / 5$ & $1 / 5$ & $1 / 3$ & $1 / 3$ & 1 & 0.107 \\
\hline \multicolumn{8}{|c|}{$\mathrm{CI}=-0.5629 \mathrm{RI}=1.45 \mathrm{CR}=-0.3882$} \\
\hline
\end{tabular}

TABLE IV. EMPLOYEE POSITIVE ATTITUDE AND BEHAVIOR OF THE INDEX WEIGHT

\begin{tabular}{|c|c|c|c|c|c|}
\hline $\mathbf{U}_{\mathbf{2}}$ & $\mathbf{U}_{\mathbf{2 1}}$ & $\mathbf{U}_{\mathbf{2 2}}$ & $\mathbf{U}_{\mathbf{2 3}}$ & $\mathbf{U}_{\mathbf{2 4}}$ & weight $\mathbf{W}_{\mathbf{2}}$ \\
\hline $\mathbf{U}_{\mathbf{2 1}}$ & 1 & 1 & 3 & 3 & 0.33 \\
\hline $\mathbf{U}_{\mathbf{2 2}}$ & 1 & 1 & 3 & 3 & 0.28 \\
\hline $\mathbf{U}_{\mathbf{2 3}}$ & $1 / 3$ & $1 / 3$ & 1 & 1 & 0.20 \\
\hline $\mathbf{U}_{\mathbf{2 4}}$ & $1 / 3$ & $1 / 3$ & 1 & 1 & 0.19 \\
\hline \multicolumn{6}{|c|}{$\mathrm{CI}=-1.01 \mathrm{RI}=0.9 \mathrm{CR}=-1.12$} \\
\hline
\end{tabular}

TABLE V. NEGATIVE WEIGHTS TO EMPLOYEE ATTITUDES AND BEHAVIOR INDEX

\begin{tabular}{|c|c|c|c|c|}
\hline $\mathbf{U}_{\mathbf{3}}$ & $\mathbf{U}_{\mathbf{3 1}}$ & $\mathbf{U}_{\mathbf{3 2}}$ & $\mathbf{U}_{\mathbf{3 3}}$ & weight $\mathbf{W}_{\mathbf{3}}$ \\
\hline $\mathbf{U}_{\mathbf{3 1}}$ & 1 & $1 / 2$ & $1 / 3$ & 0.16 \\
\hline $\mathbf{U}_{\mathbf{3 2}}$ & 2 & 1 & $1 / 2$ & 0.30 \\
\hline $\mathbf{U}_{\mathbf{3 3}}$ & 3 & 2 & 1 & 0.54 \\
\hline \multicolumn{6}{|c|}{$\mathrm{CI}=0.01 \mathrm{RI}=0.52 \mathrm{CR}=0.019$} \\
\hline
\end{tabular}

The above results are consistent with the judgment matrix consistency test, because $\mathrm{CR}<0.10$.

Step 2: Fuzzy comprehensive evaluation for human resources professional norms.

Sum up the weight allocation, order of evaluation and evaluation rate of human resources professional norms index (the evaluation rates in chart 3-1 are assumed, the organization could change the rate according its own situation), see table 6 .

TABLEVI: SUMMARY STATEMENT

\begin{tabular}{|c|c|c|c|c|c|c|c|}
\hline \multicolumn{2}{|c|}{ first level } & \multicolumn{2}{|c|}{ Second level } & \multicolumn{4}{|c|}{$\begin{array}{l}\text { Evaluation of rating and } \\
\text { valuation ratios }\end{array}$} \\
\hline Index & weight & Index & weight & $V_{1}$ & $V_{2}$ & $V_{3}$ & $V_{4}$ \\
\hline \multirow{9}{*}{$\mathbf{U}_{1}$} & \multirow{9}{*}{0.48} & $\mathrm{U}_{11}$ & 0.115 & 0.6 & 0.3 & 0.1 & 0 \\
\hline & & $\mathrm{U}_{12}$ & 0.114 & 0.5 & 0.3 & 0.2 & 0 \\
\hline & & $\mathrm{U}_{13}$ & 0.113 & 0.4 & 0.3 & 0.3 & 0 \\
\hline & & $\mathrm{U}_{14}$ & 0.112 & 0.7 & 0.2 & 0.1 & 0 \\
\hline & & $\mathrm{U}_{15}$ & 0.111 & 0.8 & 0.1 & 0.1 & 0 \\
\hline & & $\mathrm{U}_{16}$ & 0.111 & 0.8 & 0.1 & 0.1 & 0 \\
\hline & & $\mathrm{U}_{17}$ & 0.109 & 0.9 & 0.1 & 0 & 0 \\
\hline & & $\mathrm{U}_{18}$ & 0.108 & 0.5 & 0.2 & 0.3 & 0 \\
\hline & & $\mathrm{U}_{19}$ & 0.107 & 0.8 & 0.1 & 0.1 & 0 \\
\hline \multirow{4}{*}{$\mathbf{U}_{2}$} & \multirow{4}{*}{0.33} & $\mathrm{U}_{21}$ & 0.33 & 0.7 & 0.2 & 0.1 & 0 \\
\hline & & $\mathrm{U}_{22}$ & 0.28 & 0.8 & 0.1 & 0.1 & 0 \\
\hline & & $\mathrm{U}_{23}$ & 0.20 & 0.2 & 0.7 & 0.1 & 0 \\
\hline & & $\mathrm{U}_{24}$ & 0.19 & 0.3 & 0.3 & 0.4 & 0 \\
\hline \multirow{3}{*}{$\mathbf{U}_{3}$} & \multirow{3}{*}{0.19} & $\mathrm{U}_{31}$ & 0.16 & 0.2 & 0.5 & 0.3 & 0 \\
\hline & & $\mathrm{U}_{32}$ & 0.30 & 0.5 & 0.2 & 0.3 & 0 \\
\hline & & $\mathrm{U}_{33}$ & 0.54 & 0.4 & 0.3 & 0.3 & 0 \\
\hline
\end{tabular}

As shown in table 6 , accroding to $\mathrm{M}(-,+)$ operator, fuzzy comprehensive evaluation method is used to evaluate the three second grade indices:Professional norms system (U1) 、The positive attitude and behavior of staffs (U2) 、The negative attitude and behavior of staffs (U3).

First of all,we should evaluate Professional norms system (U1), As shown in table 3-1,W1= $(0.115$, $0.114,0.113,0.112,0.111,0.111,0.109,0.108$, 0.107 ) , the corresponding transformation matrix is:

$$
R_{1}=\left[\begin{array}{cccc}
0.6 & 0.3 & 0.1 & 0 \\
0.5 & 0.3 & 0.2 & 0 \\
0.4 & 0.3 & 0.3 & 0 \\
0.7 & 0.2 & 0.1 & 0 \\
0.8 & 0.1 & 0.1 & 0 \\
0.8 & 0.1 & 0.1 & 0 \\
0.9 & 0.1 & 0 & 0 \\
0.5 & 0.2 & 0.3 & 0 \\
0.8 & 0.1 & 0.1 & 0
\end{array}\right]
$$

Then we can get the result:

$$
B_{1}=W_{1} \bullet R_{1}=\left(\begin{array}{llll}
0.6649 & 0.1904 & 0.1447 & 0
\end{array}\right)
$$

In the same way,We can calculate the evaluation results of $\mathrm{U} 2$ and $\mathrm{U} 3$ :

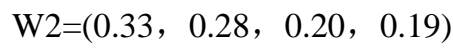

$$
R_{2}=\left[\begin{array}{llll}
0.7 & 0.2 & 0.1 & 0 \\
0.8 & 0.1 & 0.1 & 0 \\
0.2 & 0.7 & 0.1 & 0 \\
0.3 & 0.3 & 0.4 & 0
\end{array}\right]
$$

Then the positive attitude and behavior of staffs (U2) is:

$$
\begin{aligned}
& B_{2}=W_{2} \bullet R_{2}=\left(\begin{array}{llll}
0.552 & 0.291 & 0.157 & 0
\end{array}\right) . \\
& \mathrm{W} 3=(0.16,0.30,0.54) \\
& R_{3}=\left[\begin{array}{llll}
0.2 & 0.5 & 0.3 & 0 \\
0.5 & 0.2 & 0.3 & 0 \\
0.4 & 0.3 & 0.3 & 0
\end{array}\right]
\end{aligned}
$$

So the positive attitude and behavior of staffs (U2) is:

$$
B_{3}=W_{3} \bullet R_{3}=\left(\begin{array}{llll}
0.398 & 0.302 & 0.300 & 0
\end{array}\right)
$$

Based on the calculation rules of multi level fuzzy comprehensive, the result of The second stage evaluation 
should be regarded as the transformation matrix of the first stage evaluation, that is:

$$
R=\left[\begin{array}{l}
R_{1} \\
R_{2} \\
R_{3}
\end{array}\right]=\left[\begin{array}{cccc}
0.6649 & 0.1904 & 0.1447 & 0 \\
0.552 & 0.291 & 0.157 & 0 \\
0.398 & 0.302 & 0.300 & 0
\end{array}\right]
$$

So the evaluation result of Professional norms system in organization's human resources management system is:

$$
B=W R=\left(\begin{array}{lll}
0.48 & 0.33 & 0.19
\end{array}\right) \bullet\left[\begin{array}{cccc}
0.6649 & 0.1904 & 0.1447 & 0 \\
0.552 & 0.291 & 0.157 & 0 \\
0.398 & 0.302 & 0.300 & 0
\end{array}\right]
$$$$
=\left(\begin{array}{llll}
0.577 & 0.245 & 0.178 & 0
\end{array}\right)
$$

We apply the above results into a score $\mathrm{P}$, which measure the organizational human resource professional norms system is sound and reasonable or not.

$$
P=B \bullet\left[\begin{array}{l}
5 \\
4 \\
3 \\
2
\end{array}\right]=\left(\begin{array}{llll}
0.577 & 0.245 & 0.178 & 0
\end{array}\right) \bullet\left[\begin{array}{l}
5 \\
4 \\
3 \\
2
\end{array}\right]=4.399
$$

4.399 indicates that the organizational professional norms system' s complete status in one time.

When the evaluated scores of the organizational professional norms system is between 4.25 and 5 , the result illustrated the organization has a perfect professional norms system, effective running, sustainable and health development.

When the evaluated scores is between 3.6 and 4.25 , the result illustrated the staffs quality of the organization have a further improvement, and need refine the professional norms system.

When the evaluated scores is between 3 and 3.6, the result illustrated the just established professional norms system need continuous improvement. At the same time, the stability and the capacity of sustainable development are rather poor.

When the evaluated scores is between 0 and 3 , the result illustrated the professional norms system did not established, remained responsibility unclear, management disorder, low running efficiency, seriously prevent the development of the organization, its should establish the

\section{EVALUATION FOR MODEL}

The professional norms evaluation system has these following features:

Firstly, in the process of establishing the model, through experts scoring, using the analytic hierarchy process confirms the weight of each index system, and establishing the professional norms model by fuzzy comprehensive evaluation, which realize the professional norms transformation from quantitative research to qualitative research. The process of evaluation is consistent with the process of the cognition of the people. The result of its model have the scientific and operable ${ }^{\mathbf{1} 3 \mathbf{I}}$.
Secondly,Through using AHP and using the expert scoring method to score, we realize the relative importance of index,so that the model is more scientific and authoritative.Through establishing matrix, we could have a more objective recognition, and avoid the subjective factors playing a leading role in establishing the professional norms system.

Thirdly,subjective factors can influence stablishing evaluation factors 、 determining the weight of each index and evaluation value, which may affect the objective to some extent.

Fourthly, the assessors need collect more relative evaluation material.There exists prevailing information asymmetry in organations, and if employees are in internal organization over a long period of time,they are vulnerable to the impact of organizational culture ${ }^{\text {(11) }}$. Only they overcome their preferences can we achieve the scientific and correct scores.

Fifthly, difference levels, difference departments own difference organization function, difference departments should have its own professional norms. Therefore, when difference organization and department establish the professional norms system, they should proceed from realities and set up the professional norms system lived up to its own department.

\section{REFERENCES}

[1] Hu huai guan. "My views on how to develop Professional norms " [J].Journal of Hunan Agricultural University : Social Science Edition. quality education, 2007(1) : 10-11. J. Clerk Maxwell, A Treatise on Electricity and Magnetism, 3rd ed., vol. 2. Oxford: Clarendon, 1892, pp.68-73.

[2] Qiu ji. "Philosophical Thinking on the cultivation of the spirit of the occupation" [J].Journal of Renmin University of China, 2012(2) : 75-82.K. Elissa, "Title of paper if known," unpublished.

[3] Paul F. Buller, Glenn M. McEvoy, "Creating and Sustaining Ethical Capability in the Multi-National Corporation” , Journal of World Business,34(4),1999, 326-343

[4] Paul L. Schumann, "A moral principles framework for human resource management ethics',Human Resource Management Review, 11 (2001), 93-111.

[5] Ning Jing.Evaluation of contemporary professional ethics of teachers [D]. Shenyang :Shenyang Normal University.2011

[6] Mafengguang; ,Luojingfeng, “The MoralCapital Model Based on Fuzzy Comprehensive Evaluation[J]. International Conference on Engineering and Business Management:2011,574-577

[7] Zhou Qianying. "Evaluation Research of Human Resources Management for Travel Agency in Liaoning Province Based on Core Competitiveness " [D].5henyang University of Technology.December 21, 2012

[8] Wang congman,Jiang huafeng. " Application of fuzzy comprehensive evaluation method in the performance appraisal of civil servants" [J].Journal of Hebei University Of Science and Technology( social science edition).2007(1):19-23.

[9] BI Xia ,ZHU Jian-ping..Evaluation on the Quality of Civil Servants on the Basis of Fuzzy[R], 2008 International Conference on Public Administration (ICPA 4th ),636-640

[10] Wang congman, Hao zan ,Zou hongmei : "The building of the human resources professional norms system and Measure method" [J].Journal of Hebei University:(Philosophy and Social Sciences Edition),2014(6),122-125

[11] Jaime Bonache, “ Towards a re-examination of work arrangements:An analysis from Rawls "Theory of Justice” , HumanResource Management Review, 14 (2004), 395-408. 